\section{(2) OPEN ACCESS}

\title{
The use of an object: exploring physician burnout through object relations theory
}

\author{
Jo Winning
}

English, Theatre and Creative Writing, Birkbeck College, London WC1H OPD, UK

\section{Correspondence to}

Dr Jo Winning, English, Theatre and Creative Writing, School of Arts, Birkbeck College, University of London, London WC1H OPD, UK; j.winning@bbk.ac.uk

Accepted 10 April 2020
Check for updates

(C) Author(s) (or their employer(s)) 2020. Re-use permitted under CC BY-NC. No commercial re-use. See rights and permissions. Published by BMJ.

To cite: Winning J. Med Humanit Epub ahead of print: [please include Day Month Year]. doi:10.1136/ medhum-2019-011752

\section{ABSTRACT}

The crisis of physician burnout has been widely and repeatedly reported across the mainstream press and medical journals around the world, in the closing years of the second decade of the 21st century. Despite multiple systematic reviews and commentary on the scale of this 'global epidemic', understandings of both the phenomenon and the most effective interventions remain limited. Practice-based medical humanities represents the collaborative sharing of conceptual tools for understanding illness and clinical practice and the shouldering of responsibility for mapping the shape of care, in all its local, national and global contexts, thinking-with rather than critique on the profession and its practices. In keeping with this approach, this article offers a new perspective on the contemporary crisis of physician burnout by exploring the objectification of the clinician's body within the systems and practice of healthcare. Within the context of medical humanities' scholarship, discussions of objectification usually navigate towards a discussion about patient identity and its potentially reductive objectification within the frameworks of biomedical science. However, this article crosses the cultural divide between clinician and patient, and comes to focus on the objectification of the clinician herself, using object relations theory from the field of psychoanalysis to excavate the psychodynamics of care and their impact on clinicians, and the systems of healthcare in which care is delivered.

\section{INTRODUCTION: THE GLOBAL CRISIS OF PHYSICIAN BURNOUT}

In an age in which crises seem to proliferate in multiple domains of public and private spheres around the globe, the crisis of physician burnout has been widely and repeatedly reported across the mainstream press and medical journals around the world, in the closing years of the second decade of the 21st century. According to a 2019 Medscape survey that looked at physician burnout in a global context, across all countries surveyed 36\%-51\% of doctors reported having experienced burnout during their working careers and 20\%-25\% of doctors reported burnout so acute that they had considered leaving medicine as a profession. ${ }^{1}$ The Lancet editorial in July 2019 reports physician burnout as having reached 'global epidemic levels' which constitute 'a global crisis'; it cites figures of $78 \%$ of doctors in the USA and $80 \%$ of doctors in the UK as either experiencing or being at 'high risk' of burnout. ${ }^{2}$ Furthermore, The Lancet notes, while there is 'a scarcity of data on physician burnout in low-income and middle-income countries
(LMICs)', the rates of sudden death and suicide which 'are not uncommon in Asian countries' must be incorporated into the analysis of what is a global phenomenon that traverses the many different circumstances of healthcare delivery across the Global North and Global South. ${ }^{3}$

In a systematic review of 182 studies of physician burnout drawn from 45 countries, published in the Journal of the American Medical Association in late 2018, Rotenstein et al argue that burnout is 'increasingly recognised as a critical factor affecting physicians and their patients'. ${ }^{4}$ Proceeding from the Maslach Burnout Inventory description of burnout as 'a combination of emotional exhaustion, depersonalization, and low personal accomplishment caused by the chronic stress of medical practice', Rotenstein et al report findings from studies from the UK, USA, Europe and China, concluding that, given the prevalence of burnout across these different healthcare systems, 'a consensus definition of burnout and of standardizing measurement tools to assess the effects of chronic occupational stress on physicians' is urgently required, both for physician well-being and for patient safety. ${ }^{5}$

In the UK context, recent high profile policy documents produced by the public regulators, Health Education England (HEE), National Health Service (NHS) England and NHS Improvement, acknowledge and pledge to address the state of crisis of mental health issues within the healthcare workforce. ${ }^{6}$ The NHS Staff and Learners' Mental Wellbeing Commission report, based on the commission led by former HEE Chair Sir Keith Pearson and published in February 2019, observes that 'working in the healthcare sector is like no other employment environment. Daily, our staff are confronted with the extremes of joy, sadness and despair'. It notes that 'our clinical staff retain a collection of curated traumatic memories of death and dying', which sit alongside 'the horrors of extreme trauma' such as road traffic accidents, suicide and accidents and losses involving children. Acknowledging that 'the emotional labour' required in healthcare practice is 'exhausting' and that staff come to carry memories that 'like ghosts from the past may return at unexpected times', the report details the frank 'dangers' of ignoring such an affective load on NHS staff. ${ }^{7}$

This crisis of burnout prompts fundamental questions about the aetiology of the 'epidemic' and the kinds of interventions that may successfully support the healthcare workforce. Wiederhold et al's 2018 systematic review of interventions aimed to 'decrease the problem' of physician burnout finds that, across many different healthcare systems in Europe and the USA, support and treatment are 


\section{SECOND OPINION}

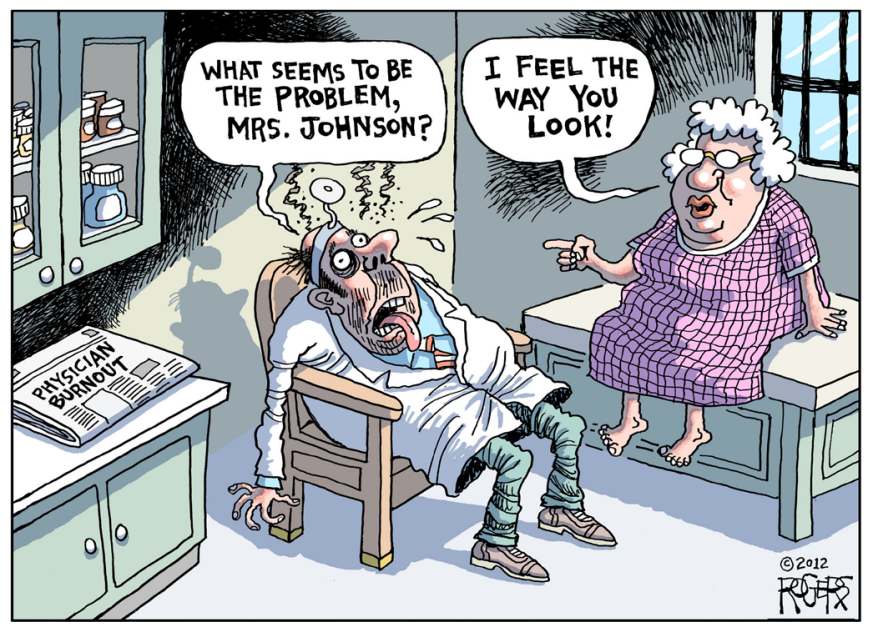

Figure 1 Rob Rogers' 'Second Opinion' (2012), reproduced with permission.

'fragmentary' at best and do not employ a 'holistic' approach to the crisis. ${ }^{8}$ In their conclusion, they recommend a suite of approaches that include 'the training of coping strategies, the training of interpersonal skills to increase social support, the management of negative emotions, the improvement of communication skills, the discussion of specific professional high-stress situations, and the use of relaxation techniques'. 9 This list of purportedly efficacious interventions places the focus, and indeed responsibility, on the individual clinician, siting the solutions to physician burnout in the bodies and minds of clinicians themselves.

One UK example of such an approach is the Practitioner Health Programme (PHP), launched in 2008 by Clare Gerada, then Chair of the Council of the Royal College of General Practitioners, following the suicide of the psychiatrist Daksha Emson, who took the life of her 3-year-old daughter at the same time. Gerada designed PHP to function as a self-referral NHS service for clinicians in medicine and dentistry with mental health or addiction issues. ${ }^{10}$ Explaining the complex barriers which prevent clinicians from crossing the divide to obtain clinical care for themselves, Gerada argued in 2009 that 'doctors have an enormous stigma associated with being sick and admitting we're just mere mortals who get depressed or drink too much'. ${ }^{11}$ PHP's multidisciplinary team of psychiatric nurses, cognitive behavioural therapists and psychiatrists continue to offer a range of inpatient and outpatient services, and currently see around 1500 clinicians a year. ${ }^{12}$ By contrast, in their July 2017 British Medical Journal (BMJ) editorial, Lemaire and Wallace describe burnout as 'a system level problem requiring a system level response' and argue that 'the wider profession and healthcare organisations urgently need to assume a greater responsibility for burnout'. ${ }^{13}$ This turn to systemic causes, rather than individual responses, is in keeping with the recent decision by the WHO to define burnout as 'an occupational phenomenon' rather than 'a medical condition', within ICD-11. ${ }^{14}$

Amidst these contrasting interpretations around the epidemic of physician burnout, this article asks what medical humanities can contribute to the critical understanding of this pressing and intractable problem. As I have previously argued, practice-based medical humanities has a crucial role to play in analysing and making visible occluded issues and dynamics within clinical practice that remain opaque to the epistemological frameworks of biomedical science. ${ }^{15}$ Thinking-with the medical profession and making recourse to a different set of conceptual tools, in this case the concepts outlined in object relations theory within the field of psychoanalysis, this article argues that previously unexamined dimensions of care itself emerge as key factors in physician burnout. ${ }^{16}$

\section{'I'VE GOT THE POWER': RECONSIDERING THE CLINICAL GAZE}

In their editorial, Lemaire and Wallace offer a productive insight, arguing that 'care providers commonly develop intense interpersonal relationships with those they care for, often prioritising others' needs over their own'. ${ }^{17}$ This turn to the act of care itself provides a first point of purchase for an object relations analysis of burnout. On her website 'Physician Burnout', UK GP Kate Little includes a cartoon by the American cartoonist Rob Rogers (figure 1) which portrays a debilitated clinician in a consultation with a seemingly much more sprightly patient. ${ }^{18}$ The clue to the clinician's state is given in a newspaper headline 'Physician Burnout', visible on the side-counter in the consulting room.

Little's choice of Rogers' political cartoon is apposite for the way it records the crisis in physician burnout and for the way in which it reverses the established dynamics of the clinical gaze. Following Foucault's delineation of the process by which the patient and her body acquire 'the status of object' in the grasp of the 'locquacious gaze' of the clinician, the paradigm that describes the patient and her body as the object of the clinical gaze, and the subsequent objectification that structures the epistemologies and methodologies of biomedical practice, is a generative commonplace in medical humanities' thought. ${ }^{19}$ The field has repeatedly excavated, theorised and named this process. ${ }^{20}$ Such objectification arises from the positivist model of scientific 'objectivity' that underpins biomedical knowledge and practice. However, as Michel Foucault's use of the geometrical metaphor of the 'perpetual spiral' to capture the complex enmeshment of power and pleasure suggests, within the clinical encounter, gazes run in both directions. ${ }^{21}$

In the cartoon, the patient is looking at the doctor, reading his visible dishevelment and exhaustion as synonyms for her own internal experience of illness. What is compelling about this visual gag is the way it visualises a little discussed psychodynamic process within the clinical encounter. In what ways might a patient's gaze impact on a clinician's subjectivity? And to what extent might the patient's illness-or the psychological impact of it-be put into the body of the clinician? Rogers' image records the ways in which 'looking' and 'feeling' can switch pole positions and the locations of 'doctor' and 'patient' become mutable in the acute and unsustainable conditions in which clinical care is delivered.

As Martha Nussbaum contends in her taxonomic analysis of the processes of sexual objectification, any and every instance of objectification 'requires a careful evaluation of context and circumstance'. ${ }^{22}$ Nussbaum writes that in all cases of objectification what is at issue is a question of treating one thing as another: one is treating as an object what is really not an object, which is, in fact, a human being'. ${ }^{23}$ Following what Rita Charon describes as the 'proliferative salience' of bringing patient stories of illness into the domain of clinical practice, I turn to examples of lived experience and narrative. In order to begin to understand some of the different iterations of the clinician's body as object. ${ }^{24}$ Below I present four narratives about medicine and clinical practice that appeared in the mainstream media, social media and the medical press over the course of 1 week in June 
2019. Each narrative, in its own way, provides different versions of the clinician's body as object.

\section{OBJECT LESSONS: NARRATIVES FROM PRACTICE}

On 12 June 2019, Dr Samantha Batt-Rawden, Chair of the grassroots organisation Doctors' Association UK (DAUK) interviewed Charles Massey, Chief Executive Officer of the General Medical Council (GMC) in a BBC Radio 4 documentary titled 'My Name Is Sammy: I'm Thinking of Leaving the NHS'. ${ }^{25}$ Batt-Rawden asked Massey on air to account for the GMC's behaviour in the case of the Dr Hadiza Bawa-Garba. Hadiza Bawa-Garba was prosecuted for Gross Negligence Manslaughter in 2015, several years after the death of a young child in her care at Leicester General Hospital in 2011. Later, in 2018, the GMC took its own tribunal service to the High Court to overturn its decision of a 12-month suspension from the medical register and have it replaced with complete erasure (being 'struck off'). This case, which constitutes one of the highest profile and most inflammatory cases of medical and systemic error in the UK in recent times, epitomises the transformation of an individual into an object for the purposes of sanction and, in the words of Charles Massey, Chief Executive Officer of the GMC, to 'maintain public confidence'. ${ }^{26}$ In response to Batt-Rawden's direct question, Massey admitted publicly that the GMC's decision had been wrong. ${ }^{27}$

Following Bawa-Garba's successful reinstatement to the medical register in 2018, DAUK launched the campaign \#LearnNotBlame. This campaign, which has attracted the support of medics at all levels within the British healthcare system, seeks to overturn the prevailing culture of blame and culpability following error that has come to dominate within the training and delivery of medicine. \#LearnNotBlame aims to replace blame culture with 'a just culture', which seeks 'to learn from events and apply this learning to bring about change'. ${ }^{28}$ In the unjust culture that prevails the persecution and prosecution of medical error, whatever the systemic errors that contextualise it, become focalised on an object, the clinician's body; further objectification of the clinician's body occurs through its institutionalisation within the systems of regulation and governance of medicine and healthcare systems.

On 13 June 2019, the GP trainee Giles Dawnay published a $B M J$ blog 'Doctor Suicide - how many more?'. He writes of the suicide of a colleague and friend in April 2019. Considering the circumstances of this death, he describes the impact of healthcare on the individuals who deliver it in the following way:

I have been in the medical world for well over a decade now, and I'm not going to lie: it is not the world that many of us thought we would enter. I don't mean that I wasn't aware this career would be hard work or that it would often leave me standing face to face with some of the most indescribable and unimaginable trauma in the lives of others. I mean that I hadn't anticipated how this world will slowly grind you down into a frazzled pulp, where support is often offered in the guise of "resilience training," an e-module, or website link. ${ }^{29}$

Dawney goes on to cite the statistics of a shockingly high suicide rate among health professionals in England between 2011 and 2015: 'Four hundred and thirty health professionals died by suicide in England between 2011 and 2015. That's almost two healthcare professionals a week'. In his own professional context he notes 'this is the third doctor suicide I've had some sort of personal link with in the past five years'. He goes on to note that these figures for suicide sit alongside the statistic that 'one third of doctors in training are estimated to be dealing with, and have symptoms of, mental health problems'. In Dawney's blog, the clinician's body can be seen as an object made vulnerable by the economic and affective conditions in which it must undertake its work of care, and at the extreme and tragic end of a continuum of stress and distress, it is an object that becomes susceptible to its own destructive impulses.

On 17 June 2019, 800,000 doctors across India went on strike to protest about dangerous working conditions in which assaults on clinicians by patients' families have become increasingly prevalent. The precipitating event was the near fatal physical assault of a trainee doctor, Paribaha Mukhopadhyay, in Kolkata in West Bengal. On the evening of 10 June 2019, Mukhopadhyay was walking down a corridor in Nil Ratan Sircar Hospital with a colleague, when he was attacked by a group of 200 people protesting the death of Mohammed Shahid, a 75-year-old man who had died in the hospital earlier that evening. ${ }^{30} \mathrm{Dr}$ Mukhopadhyay had not been involved in Mohammed Shahid's care but was the first clinician that protesters encountered in the hospital complex, when they arrived to claim that medical negligence had caused Shahid's death and that his body had not been handed over to his family in a timely fashion. Mukhopadhyay suffered life-threatening injuries, including a fractured skull that required a craniotomy.

The assault took place, The Guardian reports, in a context in which 'it has become increasingly common for doctors to be jostled, roughed up or beaten by angry relatives of the recently deceased'. ${ }^{31}$ In one of a set of nationwide public protests, doctors and medical students gathered in Vanchi Square, near the Kerala High Court in Kochi, wearing white head bandages stained with red paint on the forehead, in the place where Mukhopadhyay was injured. ${ }^{32}$ Notwithstanding the specific conditions of the healthcare system in India, in which healthcare remains unaffordable for many and public discontent runs extremely high, the assault of Paribaha Mukhopadhyay sits within an international context of violence against clinicians and healthcare workers enacted by patients and their families. ${ }^{33}$ As Elisabeth Mahase reports in the UK in January 2019, in the General Practice magazine Pulse:

More than three-quarters of doctors say they have been assaulted or threatened by a patient or their relative while practising. In a survey of around 400 doctors conducted by Doctors.net.uk, $78 \%$ said they had experienced assault, threats, or both. A total of $34 \%$ reported experiencing assault, while $59 \%$ said they had been threatened. ${ }^{34}$

These cross-cultural examples evidence the ways in which the clinician's body becomes an object that is subject to violence, a corporeal screen on to which violent enactments of grief and blame can be projected and physically actualised, an object on which retribution can be visited.

\section{DESTRUCTION AND SURVIVAL: THEORISING THE OBJECT THROUGH OBJECT RELATIONS THEORY}

For an object relations theorist the world of human selfconceptualisation, and intersubjective engagement with others in it, is structured through objects. Human beings relate to both themselves and others as objects. Learning to individuate, to become a subject in the world, from infancy to maturity, requires an understanding of others as objects that are external to the self. The first theorist of object relations, Melanie Klein, creates a model of infantile development in which the infant experiences itself and the maternal or caregiving body as, at first, conjoined. In the highly dependent state of infancy in the first couple of years of life, the infant must come to negotiate its separateness from the maternal body and, in a preverbal state, must come to manage the contents of its own psyche. 
The maternal body, principally the breast, is experienced as an object that both provides sustenance and yet, at the same time, sometimes fails to do so at the very moment the infant's hunger is experienced. In this sense, the infant must come to manage its own physical sensations, hunger and physical vulnerability, at those moments where the breast seems to fail. In what Klein terms the paranoid-schizoid phase of early infancy, the infant will 'split' the single object 'breast' into two contrasting objects: the 'good breast' (the one that gives) and the 'bad breast' (the one that fails or seemingly 'withholds').

In processes that will persist into adult life, the infant has the capacity to introject (to take in), those physical and affective states of satisfaction and comfort that are associated with what it perceives as 'the good breast'. By contrast, its anger, frustration and anxiety about the difficult physical experiences of hunger and vulnerability are projected (expelled outwards) on to what it perceives to be 'the bad breast'. In the Kleinian model, projection also functions as a means of expelling 'bad parts' of the self on to the object.

Projection is a powerful psychic process that can impact significantly on the object in question, rather like the clinician in Rogers' cartoon, who comes to embody a state resembling the patient's illness. Klein names this impact 'projective identification', a process in which these 'bad parts' might be absorbed by the object and experienced as part of its own psychic state. As Hanna Segal argues, projective identification is a state in which an individual becomes a receptacle for another's projections and 'becomes possessed by, controlled and identified with the projected parts'. ${ }^{35}$ The boundaries of an object's selfhood are porous in this respect and must bear the weight of another's often abject impulses and feelings.

In her essay 'On the Theory of Anxiety and Guilt', Klein argues that human anxiety states will commonly trigger these defence mechanisms of splitting and projection. ${ }^{36}$ Anxiety states are generated by what she calls 'danger-situations'. In infantile experiences of danger, an external threat becomes 'linked with internal danger from the death instinct' (emphasis mine). ${ }^{37}$ To put this simply, external danger perceived by the individual will trigger both primal anxieties about annihilation and primal mechanisms of defence and this is human behaviour that persists beyond childhood into adult life.

While Klein does not suggest that illness is a danger situation, I would argue it is important to understand the state of illness in these terms. In a footnote to this essay, Klein does identify the ways in which illness is an anxiety situation that can trigger a regression to very early psychic behaviours and processes. She writes that 'if a normal person [sic] is put under a severe internal or external strain, or if he falls ill or fails in some other way, we may observe in him the full and direct operation of his deepest anxiety-situations' (emphasis mine). ${ }^{38}$ This returns us to the domain of clinical care, to the world of patients, clinicians and the psychodynamics of the scene of care. Klein herself notes the persecutory and aggressive projections associated with the state of illness in a series of observations she makes about her own experience of gall bladder surgery in 1937:

When I came out of the anaesthetic I had nothing but a feeling of anger. I saw the nurse standing on (my) left-hand side in the same way as when she had given me the drug which put me to sleep, and I heard myself saying angrily, '[N]ow why did you wait so long, you can see I have woken up too early, and I have a pain where I did not have one before.' I was then told that it was some time after the operation. This feeling of anger, dissatisfaction with the world, persecution, was rather striking at the time [,] in contrast to [my] actual appreciation that it had all been done so easily, quickly, without my knowing it, [my recognition of people's] helpfulness, and [my] pleasure that it was over, which did not seem to appear at all (emphasis mine). ${ }^{39}$

While of course Klein's mental state is undoubtedly affected by the general anaesthetic and its well-known neurological side effects, and despite the historical remove of this clinical setting, there is a rich description here of the way in which anger and feelings of persecution are her primary responses to the caregivers in her immediate vicinity. If we had the nurse's narrative from this example of caregiving, what might her own description have been of delivering care to a cantankerous individual awaking from a general anaesthetic with postoperative pain? In other words, what did it feel like to be the recipient of these projections? To what extent did she experience projective identification? Or did she manage to defend against it? Most importantly, in the context of a contemporary epidemic of physician burn-out, what is the cost of being engaged in, and on, this psychic battlefield on a daily basis?

Object relations theory after Klein develops further understanding of the use of objects in human development. The paediatrician and psychoanalyst Donald Winnicott offers an account of 'object usage' that helps to texture a critical understanding of clinical care. Like Klein's, Winnicott's infant comes into its selfhood by coming to understand its separateness from the maternal or caregiving body. The maternal body is an object which provides food, comfort and safety as well as, in time, a boundary of individuality-what Winnicott terms the 'me' and the 'not-me'. ${ }^{40}$ In this sense, the infant uses the object for its own process of individuation. Importantly, Winnicott's theorisation of this developmental process delineates this use as something that involves the destruction of the object and the necessary survival of the object. He writes that: 'in the sequence [of infantile development] one can say that first there is object-relating, then in the end there is object-use [...] this change (from relating to usage) means that the subject destroys the object'. ${ }^{41}$

Such 'usage' must be repeated over and over again as the infant grows, so that the destruction must be temporary, and the object must survive its destruction, in order to continue to deliver care. As Winnicott writes: 'after "subject relates to object" comes "subject destroys object" (as it becomes external); and then may come "object survives destruction by the subject"'. ${ }^{42}$ Like Klein's recovery ward nurse, I ask here what the psychic cost to the object is. What does it mean to be the one psychically destroyed, that must also survive to bear the enactment of more destruction in order for the infant to progress? Winnicott's demarcation of good-enough mothering in part identifies the ability of the caregiver to withstand, on an hourly, daily, weekly basis, being used as an object in this way: this is the work of parenting. ${ }^{43}$ As for Klein, these psychic processes do not end with maturity but form the potential of adult behaviours and adult relating. My argument, in relation to clinical care, is that the process of individuation closely correlates to illness and recovery, with the psychodynamics of the clinical encounter mirroring something of this parent-infant relation.

To bring us back to the context of clinical care, I want to carry over these formulations of projection, projective identification, object usage and notions of destruction and survival to the clinical setting. If, following Klein, acute states of pain and illness can be understood to trigger regression to primal defence mechanisms such as splitting and projection and if, following Winnicott, the process of recovery from pain and illness, or the management of ongoing chronic illness, might be understood to mirror the process of individuation, then here we might begin to understand the texture of the psychic work done by a clinician at 
the scene of care. These deep conceptual models that explain the processes by which the clinician's body is made into an object, both in the individual, intimate dispensation of care to another human body and within the wider structures of the institutionalisation and regulation of healthcare systems. In addition, to return to both the case of Hadiza Bawa-Garba and the assault of Paribaha Mukhopadhyay, this conceptual framework might bring to light the ways in which the compulsion towards blame within global medical cultures is buttressed by, and entangled with, the same imperatives around medical error within human society at large. It provides a critical understanding of the genesis and enactment of blame and retribution in the face of medical error, both within and outwith the medical profession.

\section{SHADOWS AND OBJECTS: SPEAKING AS AN OBJECT}

In his seminal work of object relations theory The Shadow of the Object: Psychoanalysis of the Unthought Known, the contemporary psychoanalyst Christopher Bollas writes of the parental object's ability to 'cast a shadow' on the child. ${ }^{44} \mathrm{He}$ terms this the 'unthought known', a process by which parental affects are transmitted to the child non-verbally and which subsequently create feelings in the child that cannot be put into words. In the traditional account of the clinical encounter, in which the clinician holds the power to objectify the patient, Bollas' 'shadow' might be understood to fall on the patient as object. However, as the psychodynamic complexities of the act of care make clear, the shadow can also fall on the subject, who is reconfigured as an object in the scene of clinical practice.

In his early writings, Bollas describes his clinical work with autistic children in the 1980s in the following way:

Ever since I began clinical work with autistic and schizophrenic children, I have been interested in understanding the representation of one's being through object relations as well as narrative content. The autistic child cannot tell you how he feels or what his psyche is made of; he can only show you, and this he does quite well if the clinician is willing to be used as an object and to be guided via his own internal world through the subject's memory of his object relations (emphasis mine). ${ }^{45}$

Here the psychoanalyst understands his status as object, and in full and conscious knowledge of this construction, can allow himself to be used in order to facilitate communication with a young patient. This is a self-reflexive awareness brought about by the conceptual frameworks of the object relations theory Bollas incorporates in his practice, and also by the psychoanalytical training he has undertaken in order to deliver his clinical practice. As such, this kind of awareness of the ways one might be used as an object in clinical practice undoubtedly comes more easily to a psychoanalyst trained in this tradition than it would to a clinician trained in the biomedical sciences. Yet we might argue that this kind of self-reflexive understanding of being used as an object would be profoundly useful, perhaps even life-saving, in clinical practice, advancing insight and indeed self-protection in the medical clinician.

To consider what such self-reflexivity might look like, I conclude with a fourth narrative from practice in June 2019, one which nuances the conceptualisation of the clinician's body as an object and speaks to the importance of finding a vocabulary for this experience in clinical care. Ari Pence, a resident in Family and Community Medicine in Urbana, Illinois, took to Twitter on 9 June 2019 to consider the directive she once received in medical school that any demonstration of emotion with a patient, specifically crying with them, is unprofessional and should be avoided. Pence relates a clinical incident that had happened to her and a patient two nights previously:

Once in medical school I was told crying with a patient is "foolish and unprofessional". Two nights ago I delivered an IUFD [intrauterine fetal death] to woman 34 wga [weeks gestational age]. I'm currently 32 weeks. After the delivery she asked if she could place her hand on my stomach to feel a baby kick one last time (my additions) ${ }^{46}$

In an act of spontaneous, human connection, in an acute moment of devastating tragic loss, Pence's immediate response is to acquiesce to the patient's request to feel an in utero fetal kick after the devastating experience of stillbirth. Her act, involving her own body and indeed that of her own fetus, is a moment of very complex, and yet very simple, affective communication in which the clinician's body, the locus of clinical agency and knowledge, simultaneously becomes an object that can be used by a patient:

Pretty sure that attending from med school would have been quite disappointed in the way I responded...full on crying while holding her hand as she felt my baby kick. Residency is hard and beautiful and messy and oh so powerful. ${ }^{47}$

Pence's action is an intuitive and unquestioning response to a patient in emotional agony, who needs something of her body, as object, to make the utter unbearability of loss a little more bearable. To be clear here, I am in no way problematising the patient's request, it is, as Pence describes, a request that allows both of them an embodied release of deep distress in the face of terrible, life-changing loss. I do, however, want to catch hold of the thing that is hard to name here, which is the embodiment of the clinician and the fact of that body's function as object. Defying the advice once given to her by her attending physician and the directive not to cry with a patient, Pence's own tears at her patient's loss restore her subjectivity to her at the same time as her body provides comfort to the patient. This is a movement from object to subject position.

Perhaps just as important as the clinical incident itself is Pence's move to narrate it via social media. In addition to externalising the trauma of the experience, Pence creates a moment of collectivity and mutual support with her peers. The first tweet received 6482 likes, was retweeted 789 times and generated an online discussion between clinicians and healthcare professionals that ran to 131 comments. The majority of these comments were support for Pence's refusal to observe the directive she received in medical school, other narratives of shared grief with patients and reassurance to Pence that she was a good and highly professional doctor. If the positivist framework of biomedical science, with its claims to epistemological objectivity and objective practices in the clinic, has led to the objectification of the human subjects that fall under its purview, it follows that its own processes of regulation, self-definition and culture-making will similarly adhere to the 'ideal' of objectivity and require its internalisation by its practitioners. Pence's seemingly small act of tweeting about her experience, calling out to her peers to both witness it and reassure her of her professionalism, represents a refusal to be interpellated into a culture that would deny her subjectivity and construct her as the embodiment of objectivity.

Pence's narrative also offers a powerful indication of what other models of clinical care, that acknowledge both clinician and patient as subjects, might look like. This kind of care in the clinical setting looks more closely aligned to what the feminist philosopher of science Maria Puig de la Bellacasa cites as a feminist ethics of care, in which 'to value care is to recognise the 
inevitable interdependency essential to the existence of reliant and vulnerable beings' ${ }^{48}$ This is not to argue that any and every act of care should, or could, involve the degree of affective and physical connection that Pence experiences with her patient, but it is to argue that to proceed from a model of the interdependency of care would allow both patients and clinicians alike the space to exist as subjects, rather than only as objects.

In the context of a global epidemic of physician burnout and with no real clarity about which effective interventions might be made, object relations theory offers certain key concepts to help us understand the psychodynamic terrain of the subjectivities of illness, of the act of caregiving and of its impact on a clinician's body and subjective experience. Object relations theory takes us into what Julia Kristeva and Eivind Engebretsen et al define as the 'co-construction of meaning in encounters between practitioners and patients' ${ }^{49}$ Moreover, it allows us to consider how best to build what John Ballatt and Penelope Campling define as 'intelligent kindness' into healthcare systems, rather than the 'progressive dehumanisation' identified in the recent Lancet editorial. ${ }^{50}$ To the extent that both medical culture and medical humanities must urgently begin to define the parameters of physical and mental safety for the clinician, in an age when untenable demands are placed on the clinician's body, with a resultant epidemic of burnout, I would argue that the starting place must be an acknowledgement and an understanding that it is a body objectified by patient and institutional gazes, and made into an object filled with the projections and abjections of pain and illness, in the course of its everyday clinical practice.

\section{Twitter Jo Winning @jolowinning}

Contributors No contributors were involved in the writing of this article.

Funding The authors have not declared a specific grant for this research from any funding agency in the public, commercial or not-for-profit sectors.

Competing interests None declared.

Patient and public involvement Patients and/or the public were not involved in the design, or conduct, or reporting, or dissemination plans of this research.

Patient consent for publication Not required.

Provenance and peer review Not commissioned; externally peer reviewed.

Data availability statement Data are available in a public, open access repository. Data in this article are drawn from narratives freely available in the public domain.

Open access This is an open access article distributed in accordance with the Creative Commons Attribution Non Commercial (CC BY-NC 4.0) license, which permits others to distribute, remix, adapt, build upon this work non-commercially, and license their derivative works on different terms, provided the original work is properly cited, appropriate credit is given, any changes made indicated, and the use is non-commercial. See: http://creativecommons.org/licenses/by-nc/4.0/.

\section{NOTES}

1. Tim Locke (2019), "Global Physicians' Burnout and Lifestyle Comparisons," Medscape (February 2019): https://www.medscape.com/slideshow/2019-global-burnoutcomparison-6011180\#1.

2. Editorial, The Lancet 394, July 13, 2019, 93. See "Survey of America's Physicians: Practice Patterns and Perspectives" [https://www.merritthawkins.com/news-andinsights/thought-leadership/survey/2018-survey-of-americas-physicians-practicepatterns-and-perspectives/] and British Medical Association 2019 survey [https://www. bma.org.uk/collective-voice/policy-and-research/education-training-and-workforce/ supporting-the-mental-health-of-doctors-in-the-workforce].

3. Editorial, The Lancet 394, July 13, 2019, 93.

4. Lisa S Rotenstein et al. (2018), "Prevalence of Burnout amongst Physicians: A Systematic Review," JAMA 320, no. 11, 1131-50. See Christina Maslach et al Christina Maslach (2019), Maslach Burnout Inventory [https://www.mindgarden.com/ 117-maslach-burnout-inventory].

5. Rotenstein et al, "Prevalence of Burnout."

6. See NHS Improvement (2019), Interim NHS People Plan, June 3, 2019, https:// improvement.nhs.uk/resources/interim-nhs-people-plan/; Health Education England (2019), NHS Staff and Learners' Mental Wellbeing Commission, February 2019, https:// www.hee.nhs.uk/our-work/mental-wellbeing-report.

7. Health Education England, NHS Staff and Learners' Mental Wellbeing Commission, 13.

8. Brenda K Wiederhold et al. (2018), "Intervention for physician burnout: A systematic review," Open Medicine 13, 253.

9. Wiederhold et al, "Intervention for physician burnout: A systematic review," 260.

10. See https://php.nhs.uk/

11. Gerada quoted in Jo Stephenson (2009), "The Practitioner Health Programme," BMJ, March 25, 2009, 338.

12. Care Quality Commission (2019), Practitioner Health Programme Inspection Report, January 2019, http://php.nhs.uk/wp-content/uploads/sites/26/2019/03/CQC-Finalreport-2.pdf

13. Jane B Lemaire and Jean E Wallace (2017), "Burnout among doctors," BMJ 358, July 2017, 358.

14. See https://www.who.int/mental_health/evidence/burn-out/en/, accessed February 1, 2019.

15. For a definition of practice-based medical humanities, see Jo Winning (2018), "Learning to think-with: Feminist Epistemology and the Practice-based Medical Humanities," Feminist Encounters 2, no. 2, 2018, https://doi.org/10.20897/femenc/ 3888.

16. The term 'thinking-with' draws on the work of the feminist philosophers of science Isabelle Stengers and Vinciane Depret, Women Who Make A Fuss: The Unfaithful Daughters of Virginia Woolf (Minneapolis: University of Minnesota Press, 2014) and Donna J. Haraway, Staying with the Trouble: Making Kin in the Cthulucene (Durham, NC: Duke University Press, 2016).

17. Lemaire and Wallace, "Burnout among doctors," 358.

18. See https://physicianburnout.co.uk/

19. Michel Foucault (2003), The Birth of the Clinic: An Archaeology of Medical Perception (London: Routledge), xi.

20. For instance, see Rebecca Elizabeth Garden and Rebecca Garden (2007), "The Problem of Empathy: Medicine and the Humanities," New Literary History 38, no. 3 (Biocultures) (Summer): 551-67; Elizabeth Klaver (2009), ed., The Body in Medical Culture (Albany: SUNY, 2009); Mia Berglund et al. (2012), "Suffering caused by care - Patients' experiences from hospital settings," International Journal of Qualitative Studies in Health and Wellbeing 7, no. 1: doi: 10.3402/qhw.v7i0.18688; Angela Woods and Anne Whitehead (2016), The Edinburgh Companion to the Critical Medical Humanities (Edinburgh: Edinburgh University Press)

21. Michel Foucault (1980), The History of Sexuality, Vol. 1:An Introduction (USA: Vintage), 45.

22. Martha C Nussbaum (1995), "Objectification," Philosophy and Public Affairs, Vol. 24, no. 4 (Autumn), 256.

23. Nussbaum, "Objectification," 256-57.

24. Rita Charon (2008), Narrative Medicine: Honoring the Stories of Illness (Oxford: Oxford University Press, 2008), viii.

25. Listen at https://www.bbc.co.uk/programmes/m0005t3h.

26. Charles Massey, quoted in "Full General Medical Council statement over decision to strike off Jack Adcock's doctor," Leicester Mercury, January 25, 2018. For my coverage of this case see Winning, "Learning to Think-with," 2018.

27. Samantha Batt-Rawden (2019), "A change of tone from the GMC - but can they win back doctors' trust?," BMJ Opinion, June 12, 2019.

28. Cicely Cunningham (2018), "The Court of Appeal was right to reinstate Dr Hadiza Bawa-Garba," The Guardian, August 14, 2018. For the \#LearnNotBlame campaign see https://www.dauk.org/news/2018/7/24/what-is-learn-not-blame.

29. Giles Dawnay (2019), "Doctor Suicide - how many more," BMJ Opinion, June 13, 2019, https://blogs.bmj.com/bmj/2019/06/13/giles-dawnay-doctor-suicide-how-manymore/. Quoted with permission.

30. For one of many reports see "How an intern doctor's fractured skull has Kolkata up in arms as BJP blames Trinamool," India Today, June 12, 2019, https://www.indiatoday. in/india/story/kolkata-doctors-protest-nrs-medical-college-1547175-2019-06-12.

31. Amrit Dhillon (2019b), "Doctors in India strike over violent attacks by patients' families," The Guardian, June 17, 2019, https:/www.theguardian.com/world/2019/ jun/17/doctors-in-india-strike-over-violent-attacks-by-patients-families.

32. For an image of the protest see Special correspondent, "All India doctors strike: medical services across public and private sector hospitals in Kerala affected," The Hindu, June 17, 2019, https://www.thehindu.com/news/national/kerala/all-indiadoctors-strike-medical-services-across-public-and-private-sector-hospitals-in-keralaaffected/article27971430.ece.

33. For a recent discussion of the Indian healthcare system see Amrit Dhillon (2019a), "It's a godsend': the healthcare scheme bringing hope to India's sick," The Guardian March 21, 2019, https://www.theguardian.com/global-development/2019/mar/21/godsend- 
healthcare-scheme-bringing-hope-india-sick-ayushman-bharat.

34. Elisabeth Mahase (2019), "Three quarters of doctors have been assaulted or threatened at work," January 18, 2019, http://www.pulsetoday.co.uk/news/gptopics/legal/three-quarters-of-doctors-have-been-assaulted-or-threatened-at-work/ 20038110.article.

35. Hanna Segal (1974), Introduction to the Work of Melanie Klein (New York: Basic Books), 27.

36. Melanie Klein (1988), "On the Theory of Anxiety and Guilt" (1948), in Envy and Gratitude and other works, 1946-1963 (London: Virago), 25-42.

37. The Kleinian death instinct, which differs from Freud's, arises from both the visceral vulnerability experienced with the first trauma of birth and the primal aggression and survival mechanisms that accompany early infantile dependency.

38. Klein "Theory of Guilt and Anxiety," n. 2, 39.

39. Melanie Klein, "Observations after an Operation," July 1937, unpublished paper held by the Melanie Klein Trust, http://www.melanie-klein-trust.org.uk/1926-38-Londonfirst-papers. Quoted with the permission of the Melanie Klein Trust. My thanks to Harriet Barratt for introducing me to this material.

40. D.W Winnicott (1953), "Transitional Objects and Transitional Phenomena - A Study of the First Not-Me Possession," International Journal of Psycho-Analysis, 34: 89-97.

41. D.W Winnicott (1969), "The Use of an Object," The International Journal of PsychoAnalysis, 50, 712

42. D.W. Winnicott, "The Use of an Object," The International Journal of Psycho-Analysis, $50(1969), 712$

43. Winnicott outlines his concept of good-enough mothering in "Transitional Objects and Transitional Phenomena": 'the good-enough mother, as I have stated, starts off with an almost complete adaptation to her infant's needs, and as time proceeds she adapts less and less completely, gradually, according to the infant's growing ability to deal with her failure.'

44. Christopher Bollas (1987), The Shadow of the Object: Psychoanalysis of the Unthought Known (London: Free Association Books),

45. Bollas, The Shadow of the object, 5.

46. Ari Pence (@AriPence), Twitter, 11.07, June 9, 2019. Quoted with permission.

47. Ari Pence (@AriPence), Twitter, 11.09, June 9, 2019. Quoted with permission.

48. Maria Puig de la Bellacasa (2017), Matters of Care: Speculative Ethics in More Than Human Worlds (Minneapolis: University of Minnesota Press), 70

49. Julia Kristeva et al., 2018, "Cultural crossings of care: An appeal to the medical humanities," Medical Humanities 44 (2018): 55.

50. John Ballatt and Penelope Campling (2014), Intelligent Kindness: Reforming the Culture of Healthcare (London: RCPsych Publications).

51. Editorial, The Lancet 394, November 2, 2019.

\section{BIBLIOGRAPHY}

Ballatt, John, and Penelope Campling. Intelligent Kindness: Reforming the Culture of Healthcare. London: RCPsych Publications, 2014.

Batt-Rawden, Samantha. "A change of tone from the GMC - but can they win back doctors' trust?" BMJ Opinion 12 (2019).

Berglund, Mia, Lars Westin, Rune Svanström, and Annelie Johansson Sundler. "Suffering caused by care-Patients' experiences from hospital settings." International Journal of Qualitative Studies on Health and Well-being 7, no. 1 (2012), 18688.

Bollas, Christopher. The Shadow of the Object: Psychoanalysis of the Unthought Known. London: Free Association Books, 1987.

Care Quality Commission. Practitioner Health Programme Inspection Report, 2019.

Charon, Rita. Narrative Medicine: Honoring the Stories of Illness. Oxford University Press: Oxford, 2008.
Cunningham, Cicely. "The court of appeal was right to reinstate Dr Hadiza Bawa-Garba." The Guardian 14 (2018).

Dawnay, Giles. "Doctor suicide - how many more?" BMJ Opinion 13 (2019).

Dhillon, Amrit. "It's a godsend': the healthcare scheme bringing hope to India's sick.." The Guardian, 2019a. https://www.theguardian.com/global-development/2019/mar/21/ godsend-healthcare-scheme-bringing-hope-india-sick-ayushman-bharat.

Dhillon, Amrit. "Doctors in India strike over violent attacks by patients' families.." The Guardian, 2019b. https://www.theguardian.com/world/2019/jun/17/doctors-in-indiastrike-over-violent-attacks-by-patients-families.

Foucault, Michel. The History of Sexuality, Vol. 1: An Introduction. USA: Vintage, 1980. . The Birth of the Clinic: An Archaeology of Medical Perception. London: Routledge, 2003

Garden, Rebecca Elizabeth, and Rebecca Garden. "The problem of empathy: medicine and the humanities." New Literary History 38, no. 3 (2007): 551-67.

Health Education England. "NHS Staff and Learners' Mental Wellbeing Commission.", 2019. https://www.hee.nhs.uk/our-work/mental-wellbeing-report.

India Today Web Desk. "How an intern doctor's fractured skull has Kolkata up in arms as BJP blames Trinamool." India Today, 2019. https://www.indiatoday.in/india/story/ kolkata-doctors-protest-nrs-medical-college-1547175-2019-06-12.

Klaver, Elizabeth. The Body in Medical Culture. Albany: SUNY, 2009.

Klein, Melanie. Envy and Gratitude and other works, 1946-1963. London: Virago, 1988.

Kristeva, Julia, Marie Rose Moro, John Ødemark, and Eivind Engebretsen. "Cultural crossings of care: an appeal to the medical humanities." Medical Humanities 44, no. 1 (2018): $55-8$

Lemaire, Jane B, and Jean E Wallace. "Burnout among doctors." BMJ 358 (2017): 3360.

Locke, Tim. "Global Physicians' Burnout and Lifestyle Comparisons. Medscape.", 2019. https://www.medscape.com/slideshow/2019-global-burnout-comparison-6011180\#1.

Mahase, Elisabeth. "Three quarters of doctors have been assaulted or threatened at work." Pulse, 2019. http://www.pulsetoday.co.uk/news/gp-topics/legal/threequarters-of-doctors-have-been-assaulted-or-threatened-at-work/20038110.article.

Maslach, Christina. "Maslach Burnout Inventory.", 2019. https://www.mindgarden.com/ 117-maslach-burnout-inventory.

NHS Improvement. "Interim NHS People Plan.", 2019. https://improvement.nhs.uk/ resources/interim-nhs-people-plan/.

Nussbaum, Martha C. "Objectification." Philosophy and Public Affairs 24, no. 4 (1995): 249-91.

Puig de la Bellacasa, Maria. Matters of Care: Speculative Ethics in More Than Human Worlds. Minneapolis: University of Minnesota Press, 2017

Rotenstein, Lisa S, Matthew Torre, Marco A Ramos, Rachael C Rosales, Constance Guille, Srijan Sen, and Douglas A Mata. "Prevalence of burnout among physicians: a systematic review." JAMA 320, no. 11 (2018): 1131-50.

Segal, Hanna. Introduction to the Work of Melanie Klein. New York: Basic Books, 1974.

Special correspondent. "All India doctors strike: medical services across public and private sector hospitals in Kerala affected." The Hindu, 2019. https://www.thehindu.com/ news/national/kerala/all-india-doctors-strike-medical-services-across-public-andprivate-sector-hospitals-in-kerala-affected/article27971430.ece.

Stephenson, Jo. "The practitioner health programme." BMJ 25 (2009): b979.

Wiederhold, Brenda K, Pietro Cipresso, Daniele Pizzioli, Mark Wiederhold, and Giuseppe Riva. "Intervention for physician burnout: a systematic review." Open Medicine 13 (2018): 253-63.

Winnicott, D.W. "Transitional objects and transitional phenomena; a study of the first notme possession." The International Journal of Psycho-Analysis 34 no. 2 (1953): 89-97. . "The use of an object." The International Journal of Psycho-Analysis 50 (1969): $711-6$

Winning, Jo. "Learning to think-with: feminist Epistemology and the practice-based medical humanities." Feminist Encounters 2, no. 2 (2018).

Woods, Angela, and Anne Whitehead. The Edinburgh Companion to the Critical Medical Humanities. Edinburgh: Edinburgh University Press, 2016. 